\title{
LOS AVATARES DE LO NACIONAL
}

ROBERTO RETAMOSO*

Las literaturas nacionales, se sabe, históricamente son fruto de una voluntad política: la de construir no sólo una nación sino también, y esencialmente, una nacionalidad. Por ello las literaturas nacionales se constituyen como tales recién cuando aparece una "conciencia nacional" que, consignando los signos que revelan la existencia de una nación, puede reconocer en su literatura los rasgos distintivos por medio de los cuales esa nación se expresa. Se trata, así, de una perspectiva política e ideológica, que permite vincular distintos órdenes del mundo mediante correspondencias que articulan lo estético-literario con lo histórico, social, lingüístico y cultural.

$\mathrm{Si}$ a grandes rasgos ése es el modo en que las literaturas nacionales se constituyen, históricamente el mismo puede situarse en la Europa de los siglos XVIII y XIX, que es cuando la existencia de esas literaturas se institucionaliza. Y si dicha institucionalización manifiesta, por un lado, el propósito de afianzar una "conciencia nacional", por otra parte genera una disciplina novedosa que pretende dar cuenta de los "efectos de saber" de esa conciencia: la Historia Literaria. En tal sentido, la Historia Literaria, entendida como la disciplina que se ocupa de la serie diacrónica de obras y corrientes literarias por medio de la cual una nación se manifiesta, no es más que un típico producto del historicismo europeo, en sus vertientes tanto idealistas como románticas.

Sintéticamente hablando, tal sería la génesis en donde emerge la noción misma de "literatura nacional". Como puede apreciarse, esa noción se construye sobre la base de una serie de presupuestos, como los que afirman el carácter "expresivo" y "representativo" de las literaturas, o los que postulan la necesidad de interpretarlas como manifestaciones o signos que remiten a un más allá de lo literario: el ámbito fundante del sustrato nacional.

\footnotetext{
* Universidad Nacional de Rosario.
} 
Pero además, esa concepción de lo literario habria de persistir aun en aquellas perspectivas que pretendian trascender el marco filosófico del idealismo y del romanticismo, como fue el caso del positivismo decimonónico. Porque el positivismo adoptó la mirada historicista, pero mezcló en ella elementos característicos del saber naturalista. Así, la "raza" o el "medio", junto con el "momento histórico", aparecen en la perspectiva positivista como las grandes determinaciones que permiten no sólo comprender sino fundamentalmente interpretar a las manifestaciones literarias: por esa vía, la literatura nuevamente se pensaba como una forma estética cuyos contenidos, ineludiblemente, debían comprenderse por la remisión que, aunquefuese "en última instancia", establecian respecto de su contexto exterior.

La constitución de la literatura argentina como "literatura nacional" no escapa, por razones de orden histórico, cultural y político, a las características de constitución generales señaladas más arriba a propósito de las literaturas nacionales europeas. Como ha sido rigurosamente demostrado por Beatriz Sarlo y Carlos Altamirano,(1) ese proceso obedeció, también en nuestro país, a la necesidad de afianzar una "conciencia nacional" en momentos en los que las clases dominantes veían resquebrajarse la "argamasa" ideológica de su poder y de su hegemonía política.

Ese proceso se desarrolla en la época del Centenario, y está representado por algunos acontecimientos altamente significativos, como la creación de la primer cátedra universitaria de Literatura Argentina que hubo en el país -en la Facultad de Filosofía y Letras de la Universidad de Buenos Aires, a cargo de Ricardo Rojas-, o la serie de conferencias que pronunciara Lugones en el teatro Odeón sobre el Martín Fierro en 1913, y que fueron recogidas, ampliadas y editadas en 1916 bajo el título de EIPayador. Se trataba de episodios convergentes alrededor de la creencia en que existía una literatura argentina, y que esa literatura reconocía una tradición nacional, establecida por la poesía gauchesca o más especificamente aún, por el poema gauchesco de José Hernández.

De ese modo, la lectura y la interpretación que se realizaba del Martín Fierrono sólo recuperaba por parte de la crítica a la obra de Hernández, sino que además le asignaba elvalorde verdadero monumento de nuestra literatura nacional. Semejante desplazamiento en las valoraciones críticas del Martín Fierro -que habia sido ampliamente denostado por la crítica de su época-no resultaba inocente en términos políticos, puesto que esa recuperación de su sentido y de sus valores "nacionales" iba de la mano, en el caso de Lugones, de la necesidad de exorcizar la presencia de las masas inmigrantes en la escena de la cultura local. Así, el nacionalismo cultural y literario de Lugones devenía en un nacionalismo de "élite", que excluía a esas multitudes de origen foráneo de su programa y de su espacio de realización. Para ello apelaba a la idea de que el "espiritu del pueblo" o el "alma de la raza" se expresaban naturalmente a través de los versos gauchescos, y que la poesía gauchesca, al igual que las antiguas poesías épicas de Europa, no hacía más que representar el devenir histórico de nuestranacionalidad. Según esa ecuación, podia admitirse sin demasia- 
das dudas la existencia de una Nación Argentina y de una Literatura Nacional (en este caso, circunscripta por razones no sólo literarias, como ya se dijo, a la gauchesca), según un vínculo que establecía un orden de prelaciones, de determinaciones y de causalidad: porque habla un sustrato nacional que funcionaba como origen y causa del vínculo, había entonces una literatura-la gauchesca- que venía a expresar en lo subsidiario y subordinado de la escritura poética, la esenciafundante de ese sustrato matricial.

La idea de que el sustrato nacional funciona como origen y causa fundante de la literatura nativa, adquiere formulaciones puntuales tanto en Lugones como en Rojas.

En el caso de Lugones, se trata de afirmar, programáticamente, elcarácter épico del Martín Fierro, porque se partedelsupuestodeque la épica "expresa la vida heroica de la raza". En la argumentación de Lugones, sólo la literatura épica se articula necesariamente con las ideas de patria, raza o nación, porque sólo ella expresa "el modo como siente y practica la vida heroica la raza del poeta". La lírica, por el contrario, al cantar o describir "emociones generales", sólo puede expresar "la vida del hombre considerado como espíritu humano", esto es, de manera abstracta.

De todos modos, en el razonamiento de Lugones hay un nivel de generalidad del asunto, que consiste en postular una suerte de invariante: "todos los pueblos luchan por los valores de libertad y de justicia". Pero esa formulación genérica y abstracta no basta para dar cuenta de la poesía épica en su realidad empírica, ya que cada pueblo o raza combate de una manera singular -y por lo tanto histórica- por la consecución de esos valores.

Así, en Lugones se lee una especie de dialéctica que vincula al Modelo con las actualizaciones puntuales del mismo. $Y$ es esa dialéctica, precisamente, lo que le permite afirmar a Lugones el carácter épico del Martín Fierro, ya que el poema de Hemández no es otra cosa, según su punto de vista, que la encamación de lo épico ennuestra literatura. Al respecto, son notorios los esfuerzos retóricos que realiza para sostener semejante perspectiva: para Lugones, en sus contenidos, su composición e incluso en su versificación, el Martín Fierro remite a una genealogía que incluye no sólo al romancero español, sino también al Dante e incluso a los poemas homéricos. Por ello, si se trataba de replicar a las críticas habituales que recibla el poema, como la denuncia de su exceso de contracción silábica, la abundancia de prosaísmo y grosería en su texto, o la pobreza de sus rimas, el modo de hacerlo consistía en demostrar que todos esos rasgos podian reconocerse en cualquiera de esos ilustres predecesores.

Y si en Lugones se lee el énfasis con que se postula la "clasicidad" épica del Martín Fierro, en Rojas se lee más bien el espíritu historicista con el que se sitúa al poema de Hemández y a su género, en el ámbito de lo nacional.

Al respecto, un repaso de la Introducción a su Historia de la Literatura Argentina resulta sumamente ejemplar. Como es sabido, en esa Introducción Rojas se proponía establecer una serie de criterios y nociones que le permitiesen determinar y acotar 
su objeto de estudio y la perspectiva desde la cual abordarlo. En tal sentido, y a pesar de sus advertencias respecto de que no era posible "explicar nuestra evolución literaria por los procedimientos o sistemas que eximios críticos europeos han seguido", parte de un conjunto de nociones características del historicismo europeo para situar la cuestión. Esas nociones son las de suelo, raza e idioma, que aparecen en primera instancia como las grandes determinaciones de las literaturas nacionales. "Es como si los unos nacieran de los otros -dice Rojas- y todos se complementan y explican en armonioso ciclo". Así, la literatura "brota" de la lengua, como ésta brota de la raza y del suelo. Pero si la imagen ilustra en su figurabilidad la idea misma de crecimiento y despliegue histórico, como un movimiento armónico y orientado hacia un fin, el tratamiento de ese desenvolvimiento temporal es lo que suscita no pocas consideraciones por parte del historiógrafo.

En primer lugar, consideraciones referidas a los modos posibles de su cronologia. Porque Rojas advierte sagazmente que las demarcaciones o "periodizaciones" de ese continuum temporal que representa la historia de la literatura no pueden ser las mismas que delimitan al tiempo de la historia política: se trata de temporalidades distintas, indica Rojas, que no sólo no se superponen sino que incluso requieren parámetros distintos para su delimitación. Pero además, la historia de la literatura no puede reducirse a las determinaciones puramente ambientales: "el suelo, la raza, el idioma" podrán explicarnos algunos aspectos "subconscientes" de la obra como expresión de la nacionalidad, pero sólo "el genio individual, la cultura de una época, el gusto orientador de las escuelas" nos explicarán los aspectos "conscientes" de la obra como expresión de belleza. Por ello la historia literaria es también el registro de esos factores y elementos, ya que yuxtapone a las determinaciones más elementales estas otras de orden cultural, para explicar las formas y el sentido del devenir histórico.

Por consiguiente, la historia literarianopuede reducirse a las formas cronológicas de la historia política. Ello solamente puede hacerse con una finalidad "didáctica", como un modo de esquematizar y volver más fácilmente comprensibles los diversos estadios de nuestra historia espiritual. Pero resulta insuficiente para captar la sustancia del asunto, que no es otra cosa que "la conciencia nacional en función de cultura".

Para Rojas, como para Lugones, lo que verdaderamente explica el sentido histórico de nuestra literatura como "literatura nacional" es la poesía gauchesca. Porque paralelamente a las diversas escuelas y movimientos que la cronología convencional ha establecido -clasicismo, romanticismo, modernismo-, toda otra vertiente ha animado a la literatura argentina: la vertiente indígena, de la que el poema de Hernández no es sino la expresión más lograda. Esa vertiente, cree Rojas, se remonta incluso más allá de Hidalgo, para hundirse en un estadio anónimo y oral de carácter folklórico.

Así, en la perspectiva de Rojas, la poesía gauchesca es la encarnación misma de la literatura nacional. En ella se refleja el "alma argentina", dado que la poesía 
gauchescaha sido "nuestro primer ensayo de un artepropio". Pero aún más: la poesia gauchesca no sólo constituye la expresión artística de nuestro sustrato nacional -el suelo, la raza, el idioma- sino que además soporta, como una "roca primordial" o "médula vivaz" al conjunto de las manifestaciones de la literatura argentina. Por tal razón, la cronología convencional es drásticamente modificada por Rojas, o más bien, puesta en suspenso cuando abre su historia con el capítulo destinado a los gauchescos. Asi, el comienzo historiográfico se divorcia abruptamente del comienzo cronológico para fijar míticamente a la gauchesca en el origen mismo de nuestra literatura. Luego vendrían "los coloniales", "los proscriptos" y "los modernos", para hacernos ver que, después de ser violada la dimensión del suceder temporal, la cronología podia restituirse para dejarnos leer, en la sucesividad no sólo cronológica sino lógica que el mito inauguraba, la otra imagen de la literatura argentina.

La historia del nacionalismo en la Argentina -historia actualmente evanescente, cuyos vestigios se esfuman en un "ambiente de época" que parece sancionar el anacronismo de la idea misma de nacionalidad- es una historia de conflictos y bifurcaciones, que podrían representarse figuradamente, antes que con una recta, con el dibujo sinuoso de una línea que sufriera fisuras y puntos de difracción. Esos puntos de fisura y de difracción podrían ser, en ese diagrama imaginario, ciertas inflexiones que sufre la historia y el discurso del nacionalismo argentino, como las operadas con el surgimiento, hacia los años cincuenta y sesenta, de lo que dio en llamarse "nacionalismo de izquierda".

Ese nacionalismo (Hernández Arregui, Abelardo Ramos, Puiggrós) suponia, fundamentalmente, un desplazamiento del contenido mismo de la categoría de "lo nacional", puesto que ahora lo nacional se nutría de y expresaba a las grandes mayorias populares, las mismas que habian sido excluidas de la concepción nacionalista de Lugones, por volver sobre su ejemplo.

Ello era posible porque estos autores partian de otros supuestos filosóficos, ideológicos y epistemológicos, dado que adoptaban el instrumental y el punto de vista marxista para elaborar las formas de su "pensamiento nacional". Con esos recursos trataban de promover una "inteligibilidad" materialista del "ser nacional" (Hernández Arregui), despojándolo de todas las connotaciones de tipo espiritualista o metafísico con que lo habían significado los teóricos del nacionalismo oligárquico.

Y desde esa "inteligibilidad", precisamente, algunos de ellos intentaron pensar también la dinámica histórica de la literatura argentina (Imperialismo y Cultura, Crisis y Resurrección de la Literatura Argentina). De esa manera, la literatura nacional ya no era, o mejor dicho, ya no era solamente la gesta épica de la gauchesca, sino que era también toda la literatura que expresaba la causa nacional. A esa camada de autores delnacionalismo popular le sucedió, en los años setenta, una nueva camada cuyos criterios y parámetros teóricos eran más amplios y diversos (Romano, Ford, Rivera), pero que mantenían el mismo interés por los géneros y las manifestaciones populares, por los textos marginales y confinados por la sanción de la crítica al lugar 
de lo paraliterario y por lo tanto "menor": las novelas de aventuras y policiales, las historietas, la canción popular, el cine, el radioteatro, etc.

El nacionalismo popular y de izquierda sería un punto de inflexión significativo en la historia del nacionalismo argentino, ya que posteriormente las manifestaciones nacionalistas, en el plano de la cultura, se van desdibujando hasta llegar al estado actual de "difuminación" de su discurso. Y si por un lado el nacionalismo popular representa un corrimiento y un quiebre respecto de los supuestos y los criterios políticos sobre los que se construía el nacionalismo oligárquico, por otro lado representa una continuidad respecto del modo de pensar y entender a lo literario.

Porque en ambos casos se trata de pensar a la literatura como expresión. Si en un caso la literatura es expresión del "espíritu de la raza", de la "tradición nacional", en otro será expresión de lo popular, de las luchas contra la dominación no sólo de la nación sino también del pueblo, pero en ambos casos la literatura será la configuración simbólica por medio de la cual la exterioridad de lo nacional viene a manifestarse. Así, lo nacional es prácticamente un "plus" que se le adiciona a la literatura, un excedente o suplemento que, apriorísticamente, determina las formas y las condiciones de su emergencia.

La fuerza de esa interpretación -o esa interpretación como fuerza- no podía producir más que segmentaciones por lo menos discutibles en el campo de la literatura argentina. Dividida por parámetros en ocasiones reduccionistas y simplificadores, la literatura argentina devenía en el espacio de las antinomias excluyentes que impedian pensarla como conjunto -aun cuando lo fuera de manera tan conflictiva como dialéctica-: lo nacional opuesto a lo antinacional, lo popular opuesto a lo oligárquico, lo telúrico opuesto a lo cosmopolita, etc. Diríase que, apresado por sus propios supuestos, elnacionalismo literario en la Argentinano podía trascender hacia un espacio de lectura donde la literatura argentina pudiera ser pensada en sí misma y a partir de símisma. Lo cual no significa, obviamente, como algo disociado de todo tipo de vínculos con lo real, sino como un tipo de experiencia lingüística, estética, cultural y política que, generándose en condiciones particulares de realización, interpela a lo real más que lo expresa, significa al mundo más que lo representa, instituye usos y prácticas lingüisticas más que las reproduce, produce, en definitiva, un orden simbólico particular que más que entenderse como correlato y reflejo de un orden exterior constituyente, debería pensarse como otra dimensión de lo real que se vincula, según una dialéctica incesante, con los múltiples y diversos planos de eso que llamamos -no sin alguna dosis de imprecisión- el cosmos, el universo, o más enfáticamente aún, la realidad.

En un decisivo ensayo para poder pensar las dimensiones reales de la literatura argentina (El escritor argentino y la tradición),(2) Jorge Luis Borges refutó tempranamente los supuestos y los límites del nacionalismo literario. Como es público y notorio, volvió sobre las cuestiones formuladas por Rojas y Lugones alrededor de la poesía gauchesca, para refutar su creencia de que "la tradición literaria 
argentina ya existe" a partir de ella. Porque si el nacionalismo literario de Rojas y Lugones asignaba un lugar medular y esencial a la gauchesca en la génesis y en el desenvolvimiento histórico de la literatura argentina, invistiéndola con la forma y los atributos de una auténtica "tradición", la réplica borgeana consistía en la "desacralización" del género -negando cualquier visión esencialista del mismo- al postular que la literatura gauchescano era "menos artificial" que cualquier otro género literario. Menos artificial significaba, obviamente, que era tan convencional como cualquier otro, porque la literatura es precisamente eso, un conjunto deconvenciones estéticas que los hombres utilizan para significar los múltiples asuntos que desean significar por ese medio.

No obstante ello, "desacralizar" la gauchesca no implicaba, en la perspectiva de Borges, desconocer la existencia de una literatura argentina, y sobre todo de una tradición donde esa literatura pudiera inscribirse. Pero lo argentino no podia reducirse a lo gauchesco, ni siquiera como petición de principios, porque sus dimensiones se extendian, según Borges, mucho más allá de los límites que pretendía asignarle el pensamiento nacionalista. Porque si el nacionalismo creía reconocer la poesía argentina en "los rasgos diferenciales argentinos" o en el "color local" de sus enunciados, Borges reconocía a la poesía argentina en otros textos, aun en aquellos que resultaban irreductibles respecto de los cánones y los modelos propugnados por la estética del localismo.

Por tal razón, y con esa sutileza que le permitia leer como nadie lo que nadie aún había leído, Borges podía reconocer lo argentino en algunos versos de Enrique Banchs, que soslayaban toda referencia a lugares y situaciones que pudieran reconocersecomo tales. Porque esos versos, compuestos con un lenguaje afectado y distante respecto del habla nacional, venlan a significar, o más bien, a manifestar parala interpretación que de ellos realizaba Borges cierto "pudor" o cierta "reticencia" que eran típicamente argentinos.

Leyendo sutilmente el decir más allá de lo dicho, Borges desplazaba, de ese modo, el tratamiento del problema sin desconocerlo. Por ello mismo también podía reconocer en otras obras a las que el nacionalismo consagraba como verdaderos paradigmas contemporáneos de la literatura nacional, la impronta o la influencia de diversas literaturas extranjeras. Así, reconocía en la escritura de Güiraldes las huellas de Kipling o de Twain, de la misma manera que la de los poetas franceses contemporáneos. Ello significaba asimismo otra forma de ser argentino, consistente en la apropiación de la tradición de la literatura occidental no para someterse a ella sino para innovar, desde las zonas marginales de la cultura de Occidente, el legado y la historia que su tradición representa. Por eso lo argentino, para Borges, se constituia esencialmente como ejercicio del lenguaje, como actividad de escritura y de lectura, en el marco de un proceso que delimitaba espacios -lo nacional, lo universal- pero sin clausurar las fronteras que deblan acotarlos. Por las mismas razones, la literatura argentina era, paraBorges, tanto diálogo como réplica respecto de la tradición de toda la cultura occidental. Y sobre la base de esa clase de vínculos, 
Borges podia imaginar la singularidad, la especificidad de la literatura argentina, que no pasaba por la reacción xenófoba frente a lo "otro" ni por la reproducción mimética de lo extranjero. La literatura argentina, para Borges, pasaba tanto por un lenguaje como por la tonalidad con que ese lenguaje se pulsaba; por la asunción de un lugar diferencial -marginal-respecto de los discursos europeos sin ignorar por ello el lazo constitutivo, esencial, que liga a la literatura argentina con esos discursos; por la posibilidad de abordar cualquier asunto porque la literatura argentina era menos una cuestión de temas que una cuestión de sensibilidad, mirada y entonación para fomularlos.

Entre las múltiples consecuencias "teóricas" que produce la intervención borgeana, una de las más importantes es la destitución de la ecuación que vincula a la literatura argentina con la noción de literatura nacional, si por tal se entiende a una entidad estética concebida de manera esencialista. Diriase que, para Borges, ninguna forma literaria, ningún género, pueden reclamar la propiedad de semejante atributo, dado que lo argentino se desplaza a través de los géneros y las obras, para aparecer alli donde menos se lo espera. De la misma manera, cuando estamos en presencia de ciertas manifestaciones a las que calificaríamos, de modo inequívoco, como nacionales, advertimos que en su textura restallan las huellas de otras literaturas, con las que esas manifestaciones entran en íntimo contacto en el acto de su advenimiento.

Así, lo argentino puede comenzar a pensarse antes que en términos sustantivos en términos de relación: ser argentino es una forma de ser con lo otro, que involucra al vínculo en cualquier intento de definición. Semejante subversión de los axiomas del nacionalismo desbrozó el camino para que otros autores pudieran profundizar la orientación establecida por la reflexión borgeana, liberando al pensamiento sobre la literatura argentina delas determinaciones aprioristicas que fijaban, en la anterioridad pero también en la exterioridad de su esencia o sustrato matricial, las formas inequivocas de su identidad. Es conocida, por ejemplo, la representación ficcional que de estas cuestiones realizó Ricardo Piglia en Respiración Artificial,(3) y por ello no es necesario recordarlas pormenorizadamente. Pero lo que sí conviene recordar es el reordenamiento que alli establece del espacio literario argentino y sobre todo de las evaluaciones que sustentan sus límites, sus formas y sus relaciones. Porque ahora la literatura argentina no se sostiene sobre alguno de sus géneros, privilegiándolo como paradigma de lo nacional, sino que se sostiene en lo bifronte de su historia decimonónica, que incluye tanto a la gauchesca como a diversas formas del "europeísmo" practicadas desde Sarmiento en adelante. Y si el mismo Borges representa, para Piglia, la consumación histórica de esa dualidad que clausura a la literatura argentina del siglo pasado, lo verdaderamente moderno está representado por Artt, que inaugura la literatura argentina de este siglo.

La "modernidad" de Arlt es, para Piglia, una modernidad asociada a lo estilístico y a lo lingüístico. Porque Arlt escribe en contra de los cánones estilísticos dominantes en su tiempo, que prescribian los usos y las formas posibles de la lengua nacional. 
Ysiparatales cánones la lenguanacional debiaser "normalizada"y "homogeneizada" frente a las manifestaciones lingüisticas de las corrientes inmigratorias, para Arlt se trataba, en la reflexión de Piglia, de trabajar con los "restos, los fragmentos, la mezcla" de lo que "es realmente una lengua nacional".

De ese modo, en Piglia, lo argentino quedaba asimismo "desustancializado" respecto de toda clase de determinaciones apriorísticas que pretendiesen fijar su posible esencia. Pero como en Borges, nuevamente, se trataba de pensar la íntima relación que vincula a lo argentino con un determinado lenguaje, con una cierta forma de la lengua nacional. Porque son precisamente las diversas posiciones, actitudes y modalidades que los escritores asumen frente a la lengua nacional, las que determinan la función y el valor de una escritura en el espacio de la literatura argentina contemporánea. Y portal razón, si puede hablarse todavia de literaturaargentina, ello solamente es posible si se lo hace desde el único lugar o la única sustancia donde ese predicado puede sostenerse: el lugar ubicuo, abarcador, sincrético y dialógico del lenguaje nacional.

De la misma manera que la reflexión de Piglia sobre la literatura argentina no podría entenderse sin la intervención precursora de Borges, la literatura de Juan José Saer también presupone a la perspectiva borgeana en el modo y la forma con que enfrenta el tratamiento de este tipo de cuestiones. En tal sentido, el caso de Saer resulta sumamente significativo, por la manera aparentemente antitética y seguramente paradójica con la que aborda el asunto de lo nacional.

Porque hay determinados lugares de la obra de Saer donde pareciera que el asunto de lo nacional solamente puede ser planteado en términos de crítica y refutación: nos referimos, en concreto, a los ensayos publicados bajo el título de Una literatura sin atributos.(4) Alli, como es sabido, Saer se pronuncia con vehemencia en contra de todos los intentos de afirmar cualquier clase de esencia nacional de las literaturas latinoamericanas, a la que éstas deberían simplemente expresar o representar. Lo que puede haber de latinoamericano en sus obras "debe ser secundario" y venir "por añadidura", afirma Saer, porque su especificidad proviene "no del accidente geográfico" del nacimiento del escritor, sino "de su trabajo".

Notablemente, la argumentación polémica de Saer parece repetir las formas de la argumentación borgeana. Porque así como Borges refutaba la exigencia de un "color local" y de "rasgos diferenciales argentinos" para hablar de la poesía argentina, Saer refuta la exigencia de "exuberancia, frescura, fuerza, inocencia y retorno a las fuentes" que imponen ciertos medios de difusión y ciertos críticos para hablar de la literatura latinoamericana.

Esa denuncia de las estéticas canonizadas por el pensamiento nacionalista reconoce además otro rasgo en común, consistente en la crítica a toda forma de pensamiento "realista". "Mi primera preocupación de escritor [afirma Saer] es, en consecuencia, esa crítica de lo que se presenta como real y a lo cual todo el resto debe estar subordinado". En tal sentido, se advierte claramente que para Saer, lo mismo que para Borges, cualquier pretensión de someter lo literario a determinadas 
versiones aprioristicas de lo "real" es un intento tan descabellado como estéril. Porque lo literario no puede admitir ningún tipo de determinaciones, ya que escribir supone "una enorme capacidad de disponibilidad, de incertidumbre y de abandono", y esto es válido para todos los escritores, "sea cual fuere su nacionalidad". Por tal razón, insiste Saer, el escritor debe ser, "según las palabras de Musil, un hombre sin atributo [esto es] un hombre que no se llena como un espantapájaros con un puñado de certezas adquiridas o dictadas por la presión social sino que rechaza a priori toda determinación".

Pero si los ensayos referidos parecen detenerse en el plano de la mera crítica y refutación del pensamiento nacionalista, hay otros lugares de la literatura de Saer donde la admisión de lo nacional reaparece, claro que en términos incompatibles y seguramenteinaceptables paracualquier formade ese pensamiento. Porque en esos otros lugares lo nacional está despojado de todo tipo de connotación esencialista y sustantiva para ser desplazado al territorio esquivo y contingente de la infancia y del lenguaje.

De ese modo, en un bellísimo poema publicado en $E l$ arte de narrar, "A Bhlendorff",(5) Juan José Saer pudo escribir:

\author{
"Lo nacional \\ equidista sabiamente \\ de la sangre y las banderas \\ y se da, para la lengua, en el rigor. La infancia \\ es el solo pais, como una lluvia primera \\ de la que nunca, enteramente, nos secamos..."
}

Sabiamente equidistante de la raza y de los blasones donde los Estados se representan, es decir, de todas las determinaciones que el historicismo o el positivismo concibieron para definir una nacionalidad, lo nacional saereano se sitúa en el territorio ubicuo de la lengua como "rigor", esto es, como el arte verbal que el escritor practica para dialogar con el mundo. Por las mismas razones, el "solo país" -la patria auténtica- es la infancia, semejante a una lluvia primera de la que nunca podemos sustraemos. Por ello, lo nacional deviene en una experiencia verbal del escritor que, paradójicamente, es común atodos los escritores pero que se consuma no como una experienciacolectiva, gregaria-de la que el escritor serla su privilegiado exponente-sino como una experienciainevitablemente singular: la suma de "lengua, sensación, afecto, emociones, pulsiones, sexualidad" que el escritor actualiza en su práctica, y que constituye la única patria de los hombres.

En "Razones", texto preliminar a Saer por Saer,(6) la reflexión saereana arriba a una conclusión tan impecable como sarcástica:

-Por lo tanto, la patria pertenece a la esfera privada. Los que la invocan como un imperativo abstracto incurren, como en tantas ocasiones, en un abuso de confianza". 
Llevando la cuestión hasta sus límites, Saer puede liberar de ese modo al pensamiento sobre lo nacional de toda clase de determinaciones apriorísticas, para situarlo en el ámbito contingente de la experiencia singular. Ello supone emancipar la idea misma de patria o nación del lastre del realismo, para reubicarla en un plano donde lo nacional se diluye en su dimensión colectiva, empequeñeciéndose y agrandándose almismo tiempo. Esa experiencia singular de lo nacional que actualiza el trabajo del escritor -su propio modo de convocar al cosmos- es, a la vez, la experiencia más importante que pueden vivir todos los escritores del mundo, y por ello puede decirse que, en definitiva, todos los escritores viven en la misma patria: "la espesa selva virgen de lo real".

Por esa vía, lo nacional, en Saer, termina mostrándose como algo que emana de la literatura y no como algo que le es impuesto. Como en una gran vuelta de tuerca, esa noción termina siendo despojada de todas sus configuraciones habituales, para ser investida por las formas de una figura que niega su ser múltiple y plural. Pero ello no implica la lisa abolición del término y su uso, sino más bien su reutilización en otro ámbito o contexto de legitimación.

Ese contexto no es otro que el de la experiencia literaria. Liberado por fin de su sumisión respecto de cualquier versión modeladora de lo real, lo nacionales entonces esa carga interior que mueve a escribir, y a la que la lengua modula con sus formas pero también con sus residuos, sus astillas e incluso su polvo. Por eso el escritor ahora se sitúa frente al mundo desprovisto de todo tipo de anuncios y certezas, y se abandona a la empresa incierta de intentar aprehenderlo con aquello que to contingente de su propia vida le asignó como patria: una lengua, una memoria, unos afectos, una manera irrepetible de sentir la cercania inapresable de lo real.

\section{NOTAS}

(1)Cf. ALTAMIRANO, C. y SARLO, B., "La Argentina del Centenario: Campo Intelectual, Vida Literaria y Temas Ideológicos" y "La fundación de la literatura argentina", en Ensayos Argentinos, CEAL, Buenos Aires, 1983.

(2) Publicado en Discusión, libro incluido en las Obras Completas de Jorge Luis Borges, EMECE, Buenos Aires, 1974.

(3) PIGLIA, R., Respiración Artificial, Pomaire, Buenos Aires, 1980.

(4) SAER, J. J., Una literatura sin atributos, UNL, Santa Fe, 1988.

(5) SAER, J. J., El arte de narrar, UNL, Santa Fe, 1988.

(6) SAER, J. J., Juan José Saer por Juan José Saer, Celti, Buenos Aires, 1986. 